\title{
The pro-atherogenic effects of macrophages are reduced upon formation of a complex between C-reactive protein and lysophosphatidylcholine
}

\author{
Mi-Kyung Chang ${ }^{1,3+}$, Karsten Hartvigsen ${ }^{1 \dagger}$, Jewon Ryu ${ }^{2+}$, Yuna Kim² and Ki Hoon Han ${ }^{2 *}$
}

\begin{abstract}
Rationale: C-reactive protein (CRP) and lysophosphatidylcholine (LPC) are phosphorylcholine-(PC)-containing oxidized phospholipids (oxPLs) found in oxidized LDL (oxLDL), which trigger pro-atherogenic activities of macrophages during the process of atherosclerosis. It has been previously reported that CRP binds to the PC head group of oxLDL in a calcium-dependent manner. The aim of this study was to investigate the importance of binding between CRP and LPC to the pro-atherogenic activities of macrophages.

Objectives and findings: A chemiluminescent immunoassay and HPLC showed that human recombinant CRP formed a stable complex with LPC in the presence of calcium. The Kd value of the binding of the CRP-LPC complex to the receptors FCYRIA or FCYRIIA was 3-5 fold lower than that of CRP alone. The CRP-LPC complex triggered less potent generation of reactive oxygen species and less activation of the transcription factors AP- 1 and NF-kB by human monocyte-derived macrophages in comparison to CRP or LPC alone. However, CRP did not affect activities driven by components of oxLDL lacking PC, such as upregulation of PPRE, ABCA1, CD36 and PPARY and the enhancement of cholesterol efflux by human macrophages. The presence of CRP inhibited the association of Dil-labelled oxLDL to human macrophages.

Conclusions: The formation of complexes between CRP and PC-containing OxPLs, such as LPC, suppresses the pro-atherogenic effects of CRP and LPC on macrophages. This effect may in part retard the progression of atherosclerosis.
\end{abstract}

Keywords: C-reactive protein, Lysophosphatidylcholine, Macrophages, Foam cells

\section{Background}

The process of atherosclerosis is facilitated by inflammation and oxidative stress in the arterial wall [1]. Levels of C-reactive protein (CRP) are correlated with the level of inflammation and a persistently elevated serum level of CRP is a risk factor for the development of atherosclerotic cardiovascular diseases [2,3]. CRP detected in atherosclerotic plaques may be due to circulating CRP [4] or de novo CRP synthesized by macrophages and vascular smooth muscle cells [5]. CRP directly triggers the activation of Fc-gamma receptors (Fc $\gamma$ Rs) [6] and induces a number of innate immune responses including complement activation,

\footnotetext{
*Correspondence: steadyhan@amc.seoul.kr

${ }^{\dagger}$ Equal contributors

${ }^{2}$ University of Ulsan College of Medicine, Asan Medical Center, 388-1

Pungnap-2 dong Songpa-gu 138-736, Seoul, South Korea

Full list of author information is available at the end of the article
}

monocyte recruitment, and the expression of cytokines and inflammatory mediators by macrophages [7].

We previously demonstrated that CRP can specifically bind to oxidized LDL (oxLDL) but not to non-oxidized native LDL [8]. We further identified that the phosphorylcholine (PC) head group of oxidized phospholipids (oxPLs) such as oxidized 1-palmitoyl-2-arachidonoyl$s n$-glycero-3-phosphorylcholine (oxPAPC) and 1-palmitoyl2-oxovaleroyl-sn glycero-3-phosphorylcholine (POVPC) is responsible for binding to CRP [8]. The PC-containing phospholipid lysophosphatidylcholine (LPC) is found in body fluids, including blood and ascites, in a complex with albumin and native LDL particles, where it is important for the transport fatty acids and choline [9]. Oxidation dramatically increases the amount of LPC in LDL particles by more than 10 -fold, mainly through the enzymatic modification of PC by LDL-associated phospholipase A2 
(PLA2) [10,11]. Like CRP, LPC exists in the atherosclerotic arterial wall $[12,13]$ and triggers a number of proatherogenic responses [14].

In the present study, we investigated whether binding between the two potentially atherogenic factors CRP and LPC modulates their activities. We found that the activities of CRP and LPC were suppressed when they formed a complex with each other. Furthermore, costimulation of macrophages with both CRP and LPC triggered less potent pro-inflammatory activities and oxidative stress than when they were stimulated by either CRP or LPC alone.

\section{Methods}

\section{Cell culture and animal care}

Human macrophages were prepared from circulating monocytes. Briefly, fresh whole blood was withdrawn from healthy volunteers under a fasting state. Three millilitres of whole blood containing $3 \mathrm{mM}$ EDTA was carefully layered onto Picoll Hypaque $(1: 1=\mathrm{v} / \mathrm{v}, \mathrm{d}=$ $1.077 \mathrm{~g} / \mathrm{ml}$, Sigma Chemical Co.) and peripheral blood mononuclear cells were separated by centrifugation $(600 \mathrm{~g}$, $22^{\circ} \mathrm{C}, 15 \mathrm{~min}$ ) [15]. Peripheral blood mononuclear cells were immediately plated into a culture dish and incubated in RPMI medium supplemented with $20 \%$ autologous serum and antibiotics such as penicillin (100 units $/ \mathrm{ml}$ ) and streptomycin $(100 \mu \mathrm{g} / \mathrm{ml})$ until experiments were performed. 293FT cells (American Type Culture Collection, Manassas, VA) were maintained in high glucose DMEM supplemented with $10 \% \mathrm{FBS}$, penicillin (100 units $/ \mathrm{ml}$ ), and streptomycin $(100 \mu \mathrm{g} / \mathrm{ml})$ in a $5 \% \mathrm{CO} 2 / 37^{\circ} \mathrm{C}$ incubator.

The human recombinant CRP preparation used in the experiment was confirmed to be free of immunoglobulins and endotoxins [16]. All experiments with CRP were performed in the presence of $25 \mu \mathrm{g} / \mathrm{ml}$ polymyxin B to avoid interference from endotoxins. OxLDL with or without DiI $\left(1,1^{\prime}\right.$ - Dioctadecyl - 3,3,3', $3^{\prime}$ - tetramethylindocarbocyanine iodide) labelling was purchased from INTRACEL, MD, USA.

Human CRP cDNA (GeneBank accession no. NM_000567) was PCR amplified using the following primers, 5'-TGAATTCAGGCCCTTGTATC-3'(sense) and $5^{\prime}$-TCCCAGCATAGTTAACGAGC-3' (antisense). The complete nucleotide sequence was cloned into the pcDNA3.1 expression vector (Invitrogen) (CRP-pcDNA3.1) and the sequence was confirmed by direct DNA sequencing. For transfection, $1 \mu \mathrm{g}$ of CRP-pcDNA3.1 was added to $10^{5}$ macrophages in Opti-MEM (Gibco-BRL, Grand Island, NY) medium in the presence of Fugene6 agent (Roche) and incubatedfor $6 \mathrm{~h}$. For the promoter assay, 293FT cells at $75 \%$ confluency were transfected with PPRE-Luc, pRL-TK or pELAM-Luc-NFkB vector as described above using the Superfect transfection reagent
(Qiagen Inc.). The viability of the transfected cells was more than $85 \%$ as confirmed by propidium iodide staining. In a subset of experiments, macrophages were preincubated with $15 \mu \mathrm{g} / \mathrm{ml}$ of the monoclonal anti-Fc $\gamma \mathrm{RI}$ (clone:10.1, Invitrogen) and anti-Fcy RII (clone:7.3, Ancell) IgGs for $30 \mathrm{~min}$.

\section{Measurement of CRP binding to LPC}

CRP binding to LPC was determined using a chemiluminescent immunoassay as described previously [8]. In brief, LPC in PBS containing 0.27 mM EDTA was added to each well of a 96-well, white, round-bottomed microtitration plate (Dynex Technologies, Chantilly, VA) and incubated overnight at $4^{\circ} \mathrm{C}$. Nonspecific binding sites were blocked using $2 \% \mathrm{BSA} / \mathrm{PBS}$ and each well was incubated for $1 \mathrm{~h}$ with CRP in 1\% BSA/buffer A (10 mM $\mathrm{TBS} / 2 \mathrm{mM} \mathrm{CaCl} / 1 \mathrm{mM} \mathrm{MgCl}$, $\mathrm{pH}$ 7.4). The wells were washed, and the bound CRP was labelled with a rabbit anti-CRP IgG (Abcam) and alkaline phosphataselabelled goat anti-rabbit IgG (BioLegend). After incubating for 1-2 h with 50\% Lumi-Phos 530, luminescence was determined using a Dynatech luminometer (Dynex Technologies). CRP binding was quantitated as the number of relative light units detected over $100 \mathrm{~ms}$ (RLU/100 ms).

The formation of complexes between CRP and LPC was further analysed by an HPLC assay using a WatersAlliance HPLC system. LPC, CRP or CRP-LPC complexes in PBS were separated using an Apollo Silica $5 \mathrm{u}$ $(250 \mathrm{~mm} \times 4.6 \mathrm{~mm})$ column (Alltech Associates, Inc.). The solvent used for the analysis was ammonium sulfate (5 mM final conc, pH 6.0) in a solution of $60 \%$ hexane, $40 \%$ isopropanol $(\mathrm{v} / \mathrm{v})$. The flow rate used was $1.5 \mathrm{ml} / \mathrm{min}$, and the absorbance of phospholipids in the samples was measured at $205 \mathrm{~nm}$ using a Waters 2487 dual $\lambda$ absorbance detector. Data were expressed as absorbance units (AU) per running time (minutes).

\section{The binding of CRP and the CRP-LPC complex to FCyRIA and FcyRlIA}

293FT cells were transfected with Fc $\gamma$ RIA- or Fc $\gamma$ RIIApcDNA3.1 vector using Fugene6 as described above. After $24 \mathrm{~h}$, cells were replenished with DMEM medium and incubated with the stated concentration of CRP alone or the CRP-LPC complex for $30 \mathrm{~min}$ at room temperature. The cell-bound CRP was labelled with a monoclonal anti-CRP mouse IgG (clone CRP-8, Sigma; 1:200) and a FITC-conjugated goat anti-mouse secondary antibody $(10 \mu \mathrm{g} / \mathrm{ml}$ final conc, Jackson Immunoresearch). The amount of cell-associated fluorescence was estimated using flow cytometry. Nonspecific binding of CRP or CRP-LPC complex was estimated by parallel experiments using 293FT cells transfected with an empty 
vector (mock). Kd values and Bmax values of CRPbinding were calculated using PRISM software.

\section{Quantification of intracellular reactive oxygen species (ROS)}

To estimate the intracellular generation of ROS, human monocyte-derived macrophages were labelled with $5 \mu \mathrm{M}$ $\mathrm{H}_{2}$ DCFDA (Molecular Probes) for $30 \mathrm{~min}$ at room temperature and subsequently stimulated with $10 \mu \mathrm{g} / \mathrm{ml}$ CRP, LPC, or CRP-LPC complexes for $1 \mathrm{~h}$ at $37^{\circ} \mathrm{C}$. The intensity of cell-associated fluorescence, which reflects the amount of intracellular ROS, was measured and analyzed using a TCS-SP2 confocal microscopy system (Leica Microsystems, Nussloch GmbH, Germany). Spontaneous $\mathrm{H}_{2}$ DCFDA photo-oxidation was minimised by imaging cells with a single rapid scan (30 frames/sec for $512 \times 512$ pixel). The cell-associated fluorescence, which reflects the amount of intracellular ROS, in the acquired images converted to multi-coloured computerised digital images. The amount of intracellular ROS was represented by different colours where red $>$ yellow $>$ green $>$ white. In order to estimate the intensity of cell-associated fluorescence, at least 100 cells in the same image frame was used for the analysis and three independent experiments were performed in duplicate.

\section{Electrophoretic mobility shift assay (EMSA)}

Activation of AP-1, NF- $\mathrm{B}$ B and PPAR $\gamma$ in macrophages was measured by EMSA using $\left[\gamma^{-32} \mathrm{P}\right]$-ATP-labelled specific oligonucleotides containing sequences that specifically react with AP-1 (5'-CGCTTGATGACTCAGCCGGAA-3'), NFкB (5'-AGTTGAGGGGACTTTCCCAGGC-3'), and PPAR (5'-CAAACTAGGTCAAAGGTCA-3') protein, respectively (Santa Cruz Biotechnology Inc.) [17]. To ensure the bands were specific, a cold reaction was simultaneously performed with a 25-fold excess of unlabelled oligonucleotides.

\section{Promoter assay}

293FT cells were transfected with PPRE-Luc pRL-TK or pELAM-Luc-NFkB. CRP, LPC or CRP-LPC complexes were added $4 \mathrm{~h}$ after transfection, and a luciferase assay was performed $24 \mathrm{~h}$ later using a commercial kit (Promega, Madison, WI). , A promotor assay was performed under identical conditions using 293FT cells transfected with $\mathrm{pHook}^{\mathrm{TM}}$ - $\beta$-gal (Invitrogen) in order to estimate the efficacy of transfection. Obtained results were normalized relative to the amount of cellular protein (Bio-Rad protein assay kit) and $\beta$-gal activities, and expressed as luciferase activities derived from untreated transfected cells.

\section{Cholesterol efflux}

Human monocyte-derived macrophages (2000 cells per 24-well plate) were incubated with $2 \mathrm{mCi} / \mathrm{mL}\left[{ }^{3} \mathrm{H}\right]$ cholesterol for 48 hours. Cells were washed 2 times with PBS and further incubated for 4 hours in the presence of $2.5 \%$ freshly-isolated human serum. An aliquot of medium and cell lysate was counted for $\left[{ }^{3} \mathrm{H}\right]$ cholesterol radioactivity using liquid scintillation analyzer (Packard). Percent of cell-associated $\left[{ }^{3} \mathrm{H}\right]$ cholesterol released to medium via the process of efflux were calculated as follows; $\left[{ }^{3} \mathrm{H}\right]$ cholesterol medium $/$ $\left(\left[{ }^{3} \mathrm{H}\right]\right.$ cholesterol ${ }_{\text {medium }}+\left[{ }^{3} \mathrm{H}\right]$ cholesterol cell lysate $) \times$ 100 , and normalized to cell protein. Binding and uptake of DiI-labelled oxLDL by macrophages.

oxLDL labelled with the lipophilic fluorescent dye DiI in accordance with manufacturer's instructions, which can be detected at the emission wavelength of $570 \mathrm{~nm}$, was obtained from Biomedical Technologies, Inc.. Human macrophages were plated at a density of $1 \times 10^{5}$ cells per well in a 12 well plate,washed twice with RPMI 1640 medium, and then incubated with $25 \mu \mathrm{g} / \mathrm{ml}$ DiI-labelled oxLDL (DiI-oxLDL) in the presence or absence of CRP $(1-25 \mu \mathrm{g} / \mathrm{ml})$ for $30 \mathrm{~min}$ in a $5 \% \mathrm{CO}_{2} / 37^{\circ} \mathrm{C}$ incubator. In a subset of experiment, FcyRs were pre-blocked with $15 \mu \mathrm{g} / \mathrm{ml}$ of the monoclonal anti-FcyRI (clone:10.1, Invitrogen) and anti-Fcy RII (clone:7.3, Ancell) mouse antibodies at $37^{\circ} \mathrm{C}$ for $15 \mathrm{~min}$ prior to the incubation with DiI-oxLDL. The intensity of cell-associated fluorescence was analysed by flow cytometry using CELLQUEST software.

Measurement of the expression levels of CRP and cytokines The level of MCP-1, MMP-1, MMP-9, IL-1 $\beta$, and IL-8 mRNA was measured by semi-quantitative and real time PCR. Specific sequences were amplified using the primer sets and number of cycles $\left(94^{\circ} \mathrm{C}\right.$ for $30 \mathrm{~s}, 60^{\circ} \mathrm{C}$ for $1 \mathrm{~min}$ and $72^{\circ} \mathrm{C}$ for $1 \mathrm{~min}$ ) shown in Table 1 . PCR products were electrophoresed on ethidium bromide-containing agarose gels and the band intensity was measured by densitometric scanning. The linearity of the amplification was established using serial dilutions of template DNA. Real time PCR was performed with SYBR Green I using the specific primers shown in Table 1. As an internal standard, GAPDH mRNA was amplified and analysed under identical conditions using a pair of specific primers described in Table 1. The $\mathrm{Ct}$ value (the cycle number at which emitted fluorescence exceeded an automatically determined threshold) for target cDNA was corrected by the $\mathrm{Ct}$ value for GAPDH and expressed as $\Delta \mathrm{Ct}$. Data are expressed as fold changes in the amount of mRNA, which was calculated as follows; (fold changes $)=2^{(\Delta \mathrm{Ct} \text { for untreated cells }-\Delta \mathrm{Ct} \text { for treated cells) }}$.

\section{Immunoblotting assay}

Twenty micrograms of total 293FT cell lysate was separated by electrophoresis ( $300 \mathrm{~mA}$ for $2 \mathrm{~h}$ ) on a $10 \%$ 
Table 1 PCR primers and reaction conditions

\begin{tabular}{|c|c|c|c|}
\hline Gene & Gene accession number & Primers & Product size \\
\hline \multirow[t]{2}{*}{$\mid L-1 \beta$} & \multirow[t]{2}{*}{ NM_000576.2 } & 5'AGTGGTGTTCTCCATGTCCT-3' (sense) & \multirow[t]{2}{*}{398 bp } \\
\hline & & 5'-AGTCAGTTATATCCTGGCCG-3' (antisense) & \\
\hline \multirow[t]{2}{*}{ IL-8 } & \multirow[t]{2}{*}{ NM_000584.3 } & 5'-CTTTCAGAGACAGCAGAGCA-3' (sense) & \multirow[t]{2}{*}{$510 \mathrm{bp}$} \\
\hline & & 5'-CCTACAACAGACCCACACAA-3' (antisense) & \\
\hline \multirow[t]{2}{*}{ MCP-1 } & \multirow[t]{2}{*}{ NM_002981.1 } & 5'-CACTCACCTGCTGCTACTCATT-3' (sense) & \multirow[t]{2}{*}{$807 \mathrm{bp}$} \\
\hline & & 5'-TGTTGAACCAGGATTCACAGAG-3' (antisense) & \\
\hline \multirow[t]{2}{*}{ MMP-1 } & \multirow[t]{2}{*}{ NM_002421.3 } & 5'-CCATTCTACTGATATCGGGG-3' (sense) & \multirow[t]{2}{*}{$451 \mathrm{bp}$} \\
\hline & & 5'-GCCAAAGGAGCTGTAGATGT-3' (antisense) & \\
\hline \multirow[t]{2}{*}{ MMP-9 } & \multirow[t]{2}{*}{ NM_004994.2 } & 5'-GAGATTGGGAACCAGCTGTA-3' (sense) & \multirow[t]{2}{*}{$569 \mathrm{bp}$} \\
\hline & & 5'-TGCAGGATGTCATAGGTCAC-3' (antisense) & \\
\hline \multirow[t]{2}{*}{ GAPDH } & \multirow[t]{2}{*}{ NM_002046.4 } & 5'-GACCCCTTCATTGACCTC-3' (sense) & \multirow[t]{2}{*}{$360 \mathrm{bp}$} \\
\hline & & $\overline{5^{\prime} \text {-GCTAAGCAGTTGGTGGTG-3' (antisense) }}$ & \\
\hline
\end{tabular}

SDS-PAGE gel and transferred onto an Immobilon PVDF membrane (Millipore Corporation, Bedford, MA). Blots were blocked with 5\% skimmed milk in TBS with $0.01 \%$ Tween-20 (TBS-T) for $60 \mathrm{~min}$ and incubated overnight at $4^{\circ} \mathrm{C}$ with the following antibodies; mouse monoclonal anti-CD36 (Clon: SMO; Ancell corporation, MN USA), mouse monoclonal anti-ABCA1 (AB.H10; Abcam corporation Cambridge UK), mouse monoclonal anti-PPARY (Santa Cruz biotechnology. INC) and mouse monoclonal anti- $\alpha$-actin (Sigma Chemical Co. St. Louis, MO). The membrane was washed in TBS-T for $10 \mathrm{~min}$ three times and incubated with goat anti-mouse HRP (1:10000, Jackson Immuno Research Lab Inc) for $60 \mathrm{~min}$ at room temperature. After washing with TBS-T for 10 min three times, the membrane was developed by a chemiluminescent detection kit (ECL-kit, Amersham, Piscataway, NJ). The amount of signal generated was quantified by scanning photo-densitometry using a MULTI-IMAGE analysis system and Quantitation software (Bio-Rad Laboratories Inc., Hercules, CA).

\section{Statistical analysis}

SPSS was used to perform statistical analysis. Differences between two groups were determined by unpaired Student $t$ test. Differences between multiple groups were determined by two-way analysis of variance (ANOVA), where appropriate. Differences were considered significant when $\mathrm{p}<0.05$. The binding of the CRP-LPC complex to Fc $\gamma$ RIA and IIA was analysed using PRISM 3.0 software.

\section{Results}

\section{CRP forms a complex with LPC in a calcium-dependent} manner

A chemiluminescent immunoassay showed that CRP bound to LPC in a dose-dependent manner (Figure 1A, $\mathrm{p}<0.01$ ANOVA). The CRP binding to LPC was calciumdependent, as binding was abolished by calcium depletion or the addition of EDTA (data not shown). HPLC showed that the peak representing LPC gradually disappeared as CRP was added, while a new peak was detected at a different position, suggesting LPC forms a complex with CRP. The LPC peak at the original position became undetectable when CRP was added at a ratio of 1:1(w:w) and this ratio was used for subsequent experiments in this study (Figure 1B). HPLC confirmed that the CRP-LPC complex was stable for at least $48 \mathrm{~h}$ at $37^{\circ} \mathrm{C}$ (data not shown).

The CRP-LPC complex binds less efficiently to FcyRIA and FcyRIIA in comparison to CRP alone

FcyRIA or FcyRIIA was expressed in 293FT cells, the CRP-LPC complex was added, and the level of binding of the complex to cells was estimated by flow cytometry analysis. The $\mathrm{Kd}$ values of CRP-LPC complex binding to FcyRIA or FcyRIIA were 3-5 times higher in comparison to CRP alone, indicating binding of CRP to LPC lowers the binding affinity of CRP for FcyRs (Figure 1C and 1D). However, the maximal binding of the CRP-LPC complex to either FcyRIA- or Fc $\gamma$ RIIA, as estimated by Bmax values, was comparable to that of CRP alone.

\section{The CRP-LPC complex induces less potent intracellular} ROS production and less activation of AP-1 and NF-kB Confocal microscopic images showed that $\mathrm{H}_{2}$ DCFDAlabelled macrophages derived from human monocytes displayed cell-associated fluorescence after treatment with CRP or LPC alone for $30 \mathrm{~min}$, indicating the generation of ROS. The level of intracellular ROS produced by the CRP-LPC complex was less potent (Figure 1E). The activation of AP-1 and NF-kB by CRP or LPC was confirmed by EMSA. As observed for ROS generation, the level of AP-1 and NF-kB activation induced by the CRP-LPC complex was significantly lower than that induced by CRP or LPC alone (Figure 1F). 
Binding of CRP and LPC reduces the production of pro-inflammatory mediators by human macrophages Real time PCR showed that both CRP and LPC stimulated expression of MMP-1, MMP-9, MCP-1, IL-1 $\beta$, and IL- 8 by human macrophages after $24 \mathrm{~h}$ (Table 2 ). CRP induced expression of MMP-1 from an undetectable basal level and this effect was suppressed by the addition of LPC. Similarly, the induction of MMP-9, MCP-1, IL- $1 \beta$ and IL- 8 by LPC was antagonized by CRP.

CRP does not suppress PPRE activation induced by oxidized linoleic acid (oxLA) lacking PC

A promoter assay was performed using FcyRIA(+) 293FT cells, which clearly showed that both CRP and LPC induced
A

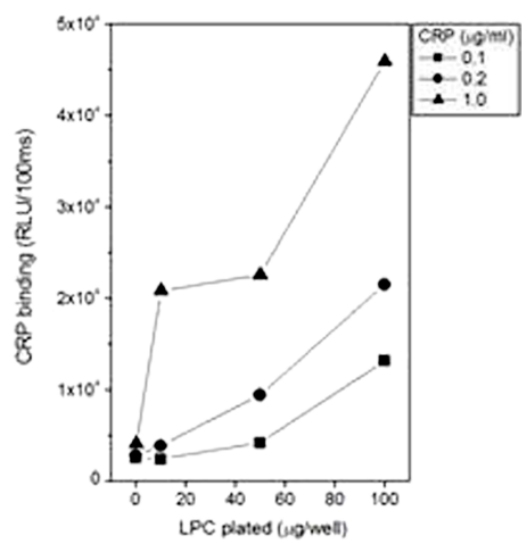

C

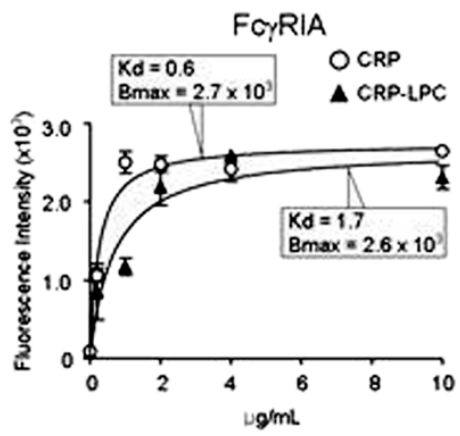

E
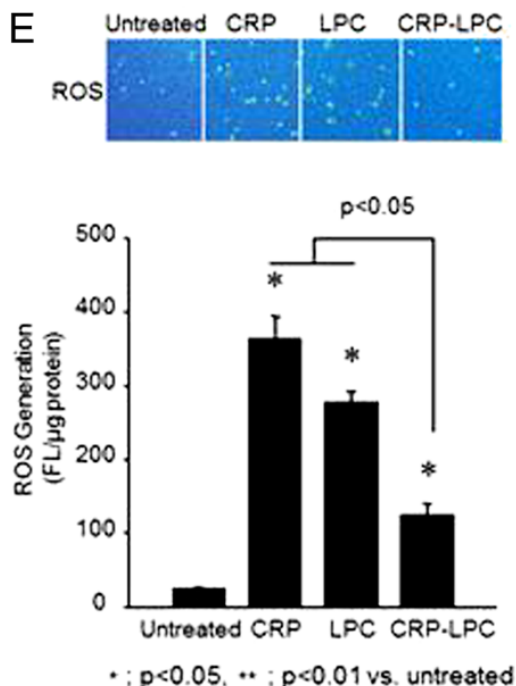

B

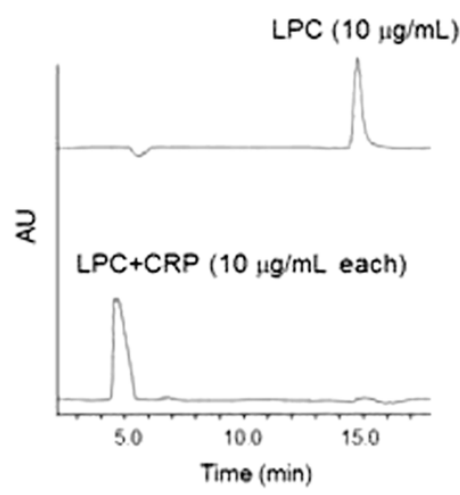

D
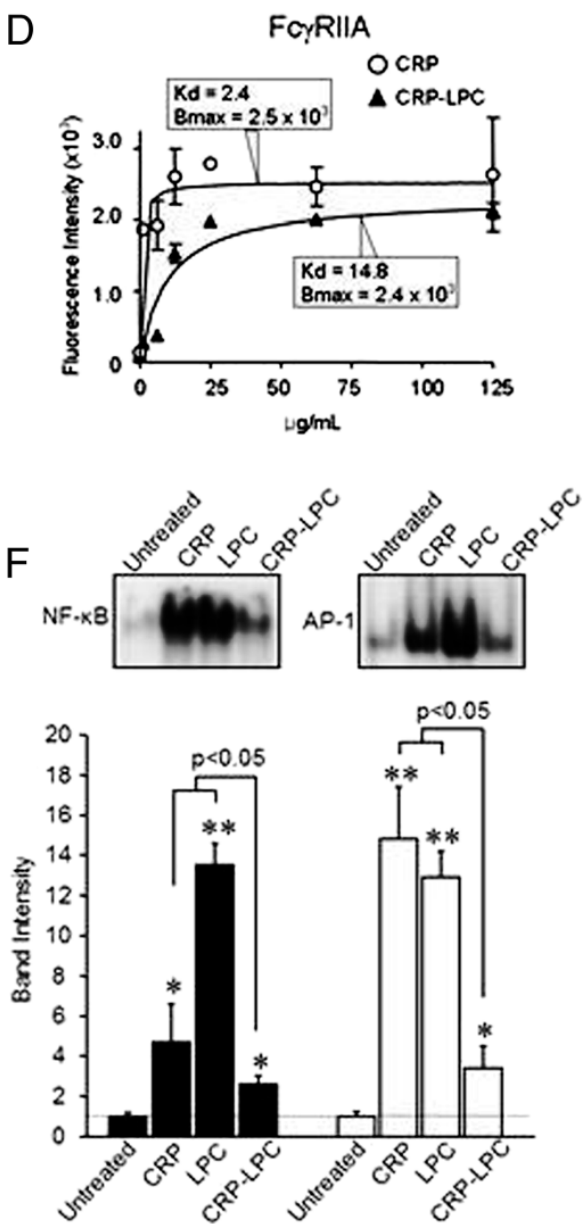

Figure 1 (See legend on next page.) 
(See figure on previous page.)

Figure 1 Complex formation between CRP and LPC and the impact of the CRP-LPC complex on FcyRs binding kinetics and macrophage activities. (A). CRP bound to LPC-coated plate was detected with a specific anti-CRP antibody and alkaline phosphatase-labelled secondary antibody. Data were expressed as relative light units over $100 \mathrm{~ms}$ (RLU/100 ms). The figure represents one of three independent experiments. (B). LPC in the presence or absence of CRP $(10 \mu \mathrm{g} / \mathrm{ml}$ each in the presence of $2 \mathrm{mM}$ calcium) was detected by HPLC using an Apollo Silica 5u column. Data are expressed as absorbance units (AU) at $205 \mathrm{~nm}$ over time. The figure represents one of three independent experiments. (C and D). The specific binding of CRP or CRP-LPC (up to $10 \mu \mathrm{g} / \mathrm{ml}$ ) to 293FT cells transfected with FCyRIA (C) or FCyRIIA (D) was obtained as described in the Methods section. Data shown are mean values \pm S.D. from three independent experiments. Kd and Bmax values were analysed using Prism software. (E). $\mathrm{H}_{2}$ DCFDA-labelled human macrophages were stimulated with $10 \mu \mathrm{g} / \mathrm{ml}$ CRP, LPC or CRP-LPC complexes for $30 \mathrm{~min}$ and the generated intracellular ROS (red > yellow > green > white in the upper panel) was detected by confocal microscopy. Data represent mean values \pm S.D. of the amount of intracellular ROS from three independent experiments. (F). NF-kB and AP-1 activity of human macrophages treated with $10 \mu \mathrm{g} / \mathrm{mL} C R P$, LPC, or CRP-LPC complexes were measured by EMSA. The EMSA image represents one of three independent experiments. Data represent mean values \pm S.D. from three independent experiments.

NF- $\mathrm{KB}$ activation (Figure 2A). As expected, CRP inhibited LPC-induced NF- $\mathrm{KB}$ activation in a dose-dependent manner $(\mathrm{p}<0.01$, ANOVA). We confirmed that oxLA, an oxidized moiety in oxLDL which lacks PC, induced PPRE activation. CRP did not activate PPRE nor did it affect PPRE activation induced by oxLA (Figure 2B, $\mathrm{p}>0.05$ ANOVA).

The degree of lipid accumulation in macrophages can also be determined by the efficacy of cholesterol efflux. oxLDL upregulated the expression level of genes that promote cholesterol efflux; e.g., ABCA1, PPAR $\gamma$, and CD36 (Figure 2C). As expected following the upregulation of these genes, oxLDL dramatically increased cholesterol efflux by human macrophages from $2.6 \pm 3.7 \%$ to $32.2 \pm 8.6 \%$ $(\mathrm{p}<0.05)$ and the presence of CRP did not significantly affect oxLDL-stimulated cholesterol efflux (Figure 2D).

\section{CRP inhibits foam cell formation in vivo and oxLDL uptake by human macrophages}

We studied whether CRP affects oxLDL uptake by human macrophages. Flow cytometry showed that the association of DiI-oxLDL with human macrophages was mediated predominantly through the scavenger receptor CD36, as an anti-CD36 antibody could inhibit $>60 \%$ of the cell-associated fluorescence (Figure 3). CRP inhibited the association of DiI-oxLDL to macrophages in a dosedependent manner. CRP significantly inhibited $>30 \%$ of the CD36-dependent oxLDL uptake (Figure 3; $\mathrm{p}<0.05$, ANOVA). Unlike CD36, the functional blocking of FcyRI (CD64) and FcyRII (CD32) did not affect the association of Dil-oxLDL with human macrophages regardless of the presence of CRP (Figure 3).

\section{Discussion}

In this study we have shown that CRP forms a stable complex with LPC, a major PC-containing phospholipid in oxLDL, supporting our previous observations that exposure of the PC head group of unsaturated fatty acids following oxidation is a prerequisite for binding to CRP [8]. Previous studies have described how two $\mathrm{Ca}^{2+}$ binding sites in the CRP pentamer [18] directly bind to two

Table 2 Changes in the mRNA expression levels of MMP-1, MMP-9, MCP-1, IL-1 $\beta$ and IL-8 in response to the CRP-LPC complex

\begin{tabular}{|c|c|c|c|c|}
\hline mRNA & Untreated & CRP & LPC & CRP-LPC \\
\hline Concentration & & $10 \mu \mathrm{g} / \mathrm{ml}$ & $10 \mu \mathrm{g} / \mathrm{ml}$ & $10 \mu \mathrm{g} / \mathrm{ml}$ each \\
\hline \multicolumn{5}{|c|}{$\Delta \mathrm{Ct}$ of average \pm S.D. } \\
\hline \multirow[t]{2}{*}{ MMP-1 } & ND & $10.63 \pm 0.76$ & $9.78 \pm 3.26$ & $13.63 \pm 1.08^{\otimes}$ \\
\hline & & $(\mathrm{NC})$ & $(\mathrm{NC})$ & (NC) \\
\hline \multirow[t]{2}{*}{ MMP-9 } & $4.82 \pm 0.19$ & $3.50 \pm 0.34^{*}$ & $3.47 \pm 0.28^{*}$ & $5.10 \pm 0.26^{\otimes}$ \\
\hline & & $(2.6)$ & $(2.5)$ & $(0.8)$ \\
\hline \multirow[t]{2}{*}{ MCP-1 } & $4.38 \pm 0.06$ & $1.40 \pm 0.08^{*}$ & $2.18 \pm 0.02^{*}$ & $2.95 \pm 0.01 * \nabla$ \\
\hline & & (7.9) & $(4.6)$ & $(2.7)$ \\
\hline \multirow[t]{2}{*}{ IL-1及 } & $12.04 \pm 0.29$ & $1.63 \pm 0.01^{*}$ & $10.46 \pm 0.29^{*}$ & $2.38 \pm 0.21^{* \otimes}$ \\
\hline & & (3258.5) & (3.0) & (809.0) \\
\hline \multirow[t]{2}{*}{ IL-8 } & $9.34 \pm 0.08$ & $0.73 \pm 0.04^{*}$ & $7.83 \pm 0.02^{*}$ & $3.02 \pm 0.48^{* \otimes}$ \\
\hline & & $(389.4)$ & $(2.9)$ & (79.6) \\
\hline
\end{tabular}

Human macrophages were incubated with $10 \mu \mathrm{g} / \mathrm{ml} \mathrm{CRP,} \mathrm{LPC} \mathrm{or} \mathrm{CRP-LPC} \mathrm{for} 24 \mathrm{~h}$ and mRNA expression levels of MMP-1, MMP-9, MCP-1, TNF-a, IL-1 $\beta$, IL-8 and GAPDH were estimated by real-time PCR. Data analyzed were from three independent experiments. Fold changes in mRNA levels are presented, which were calculated from $\Delta C t$ values as described in the Methods section.

Each PCR was performed with 40 amplification cycles. ${ }^{*} ; \mathrm{p}<0.05$ vs. Untreated macrophages. ${ }^{\otimes} ; \mathrm{p}<0.05$ vs. CRP and LPC treated macrophages. Significance values were calculated using a the unpaired $t$ test. ND; not detectable within 40 cycles of amplification, NC; non-calculable. 
A

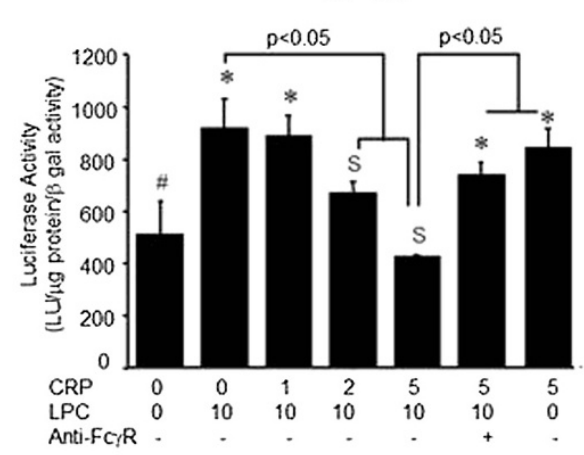

C
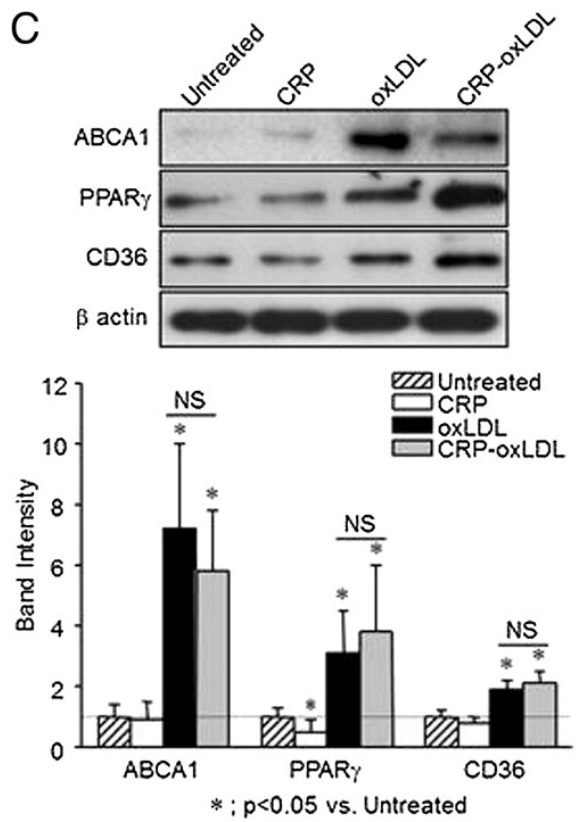

B PPRE
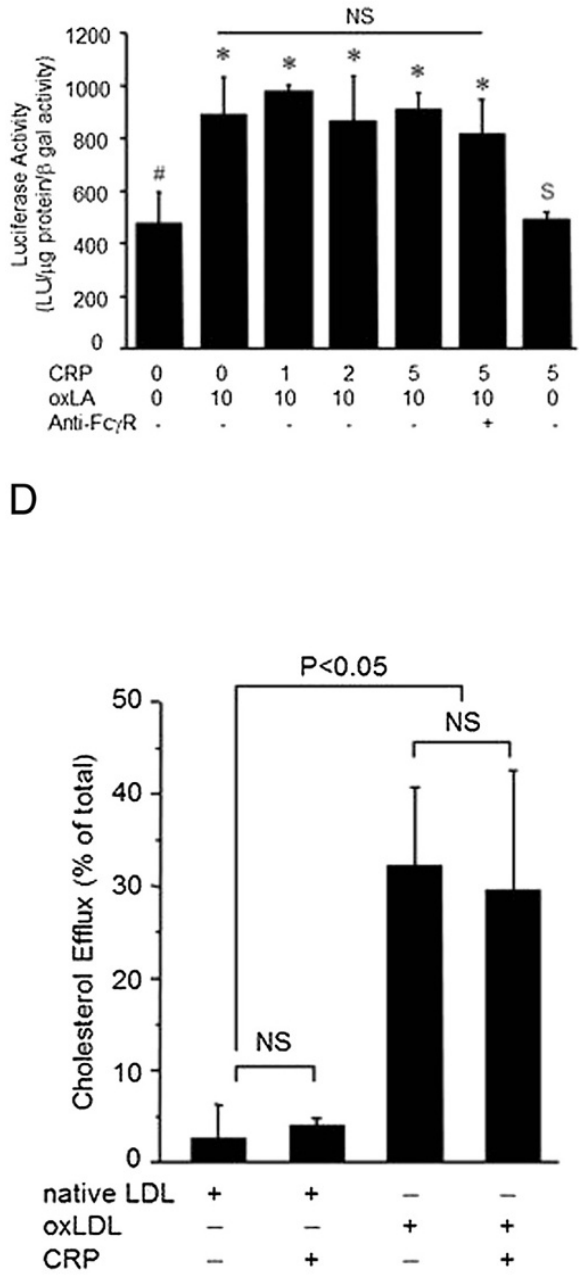

Figure 2 CRP sustains oxLDL-stimulated expression of ABCA1, PPARy, CD36 and PPRE leading to cholesterol efflux. (A and B). 293FT cells transfected with pELAM-Luc-NFKB-Luc pRL-TK (A) or pELAM-Luc-PPRE-Luc PRL-TK (B) were treated with hCRP (up to $5 \mu \mathrm{g} / \mathrm{ml} / 24 \mathrm{~h}$ ), LPC or

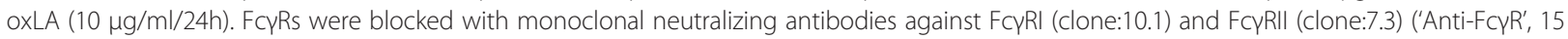
$\mu \mathrm{g} / \mathrm{ml}$ each). Data represent mean values \pm SD of luciferase activity of the cell lysates after adjusting relative to the $\beta$-gal activity and the protein content. *; p $<0.05$ vs the control (\#), S; not statistically significant vs. the control (\#), NS; not statistically significant each other. (C). Human macrophages were treated with $10 \mu \mathrm{g} / \mathrm{ml} / 24 \mathrm{~h} \mathrm{hCRP}$, fully oxidized LDL (oxLDL), or a mixture of hCRP-oxLDL, and the protein expression levels of ABCA1, PPARY, and CD36 were estimated by an immunoblot assay. The immunoblotting image represents one of three independent experiments. Data are given as mean \pm SD from three independent experiments. *; $p<0.05$ vs. untreated, NS; not statistically significant. (D). Human macrophages were incubated with $2 \mathrm{mCi} / \mathrm{mL}\left[{ }^{3} \mathrm{H}\right]$ cholesterol for $24 \mathrm{~h}$, and $10 \mathrm{\mu g} / \mathrm{ml}$ oxLDL or hCRP was added and maintained further for $24 \mathrm{~h}$. Unbound $\left[^{3} \mathrm{H}\right]$ cholesterol was washed off and cells were further incubated for $4 \mathrm{~h}$. The percentage of cell-associated $\left[{ }^{3} \mathrm{H}\right]$-cholesterol released into the media in $4 \mathrm{~h}$ was obtained by performing a cholesterol efflux assay as described in the Methods. Data are given as mean \pm SD from three independent experiments. NS; not statistically significant. CRP does not inhibit oxLDL-stimulated cholesterol efflux by human macrophages.

oxygen atoms within a phosphate group of PC [19], while specific binding sites for FcyRs are located on the opposite plane of CRP [20]. Electron microscopy studies have demonstrated that binding of CPR to PCcontaining ligands, including LPC, induces the partial dissociation of the pentameric structure of CRP to an open-ring-like structure [21]. Results of our binding assay clearly showed binding between CRP and LPC decreases their binding affinity to Fc $\gamma$ RI and II without changing their maximal binding capacity. Therefore, it is possible that CRP-bound LPC may not directly interfere with binding of CRP pentamers to Fc $\gamma$ Rs. Instead, conformational changes in the LPC-bound CRP pentamer may distort binding sites for Fc $\gamma$ Rs, resulting in less 


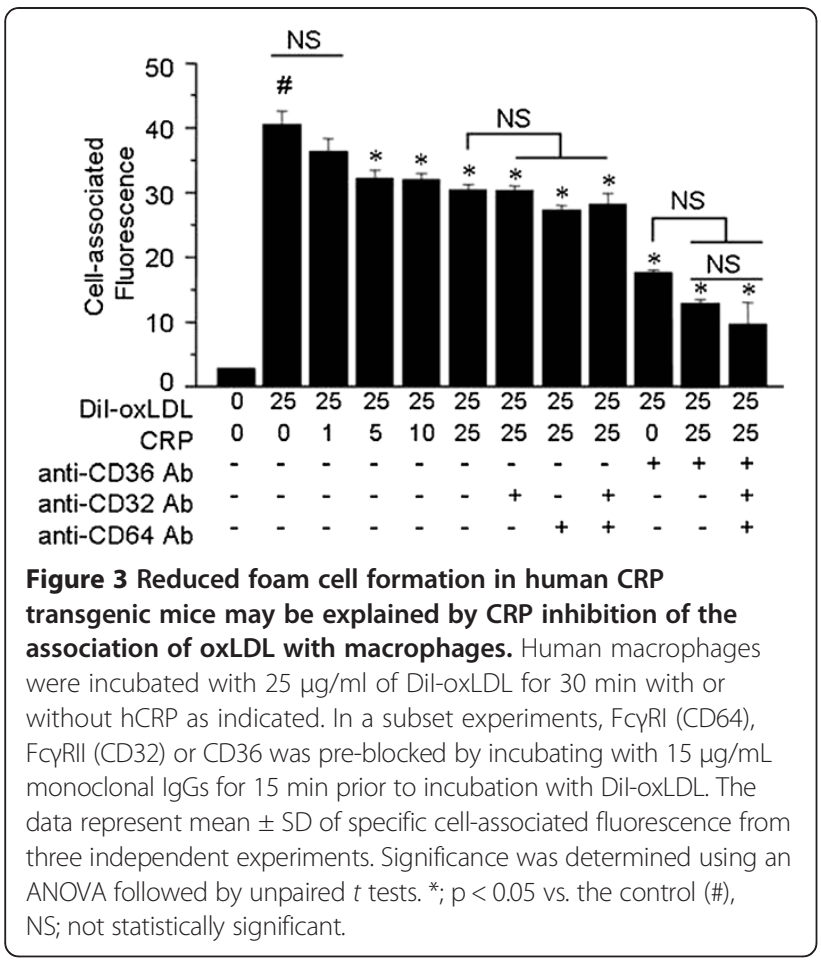

efficient binding of the CRP-LPC complex to Fc $\gamma$ Rs. This may lead to less potent activation of $\mathrm{Fc} \gamma \mathrm{Rs}$, thus reducing NF-kB activation [22] and the generation of ROS [23], as observed in this study.

The formation of atherogenic foam cells is stimulated by defects in cholesterol efflux. Macrophages regulate cholesterol efflux through uptake of oxLDL by CD36 and release of oxLDL by ABCA1. In this study, oxLDL profoundly upregulated the expression of CD36 and ABCA1 in macrophages, and enhanced cholesterol efflux through PPAR $\gamma$ activation as previously described [24]. Interestingly, we found that the presence of CRP did not affect oxLDL-stimulated cholesterol efflux or modify regulation of the related genes. This observation suggests that CRP does not affect the activities of moieties lacking PC in oxLDL, such as oxysterol-stimulated LXR expression and/or oxidized fatty acid-induced PPARY upregulation [25], which promote cholesterol efflux.

Our hypothesis was further confirmed using a promoter assay, in which CRP blocked NF- $\mathrm{kB}$ activation by PC-containing LPC, while PPRE activation induced by PC-lacking oxLA was unaffected. Moreover, the in vitro experiments showed that CRP interferes with the binding of oxLDL to macrophage scavenger receptors such as CD36. We previously obtained similar findings showing that anti-PC antibody (EO6) binds to the PC-epitope in oxLDL and inhibits the binding of oxLDL to macrophages [26]. A previous study also showed that complexes of CRP and enzymatically-modified LDL (E-LDL) induced less effective foam cell formation when compared to E-LDL alone [27]. However, several other studies are contradictory to ours, and report that the presence of CRP may enhance the uptake of oxLDL through FcyRs. In these studies, the U937 human leukemic monocytic cell line representing undifferentiated form of monocytes [28] or monocytes freshlyrecruited to inflammatory foci [29] were used. In this study, we used fully-matured human macrophages that had a 12-20 fold higher expression of CD36, in comparison to immature monocytes, which mediates $40-$ $50 \%$ of oxLDL binding [30]. We found that the uptake of oxLDL was mostly through CD36, and that FcyRdependent trafficking of CRP-oxLDL complexes was minimal. A previous study showed that the proteasome activity of intra-plaque macrophages in hCRP/ApoB ${ }^{100 / 100}$ / $\mathrm{LDLR}^{-1-}$ mice was enhanced by CRP [31], which resulted in degradation of oxidized and misfolded proteins and reduced oxidative stress. Taken together with our findings, it is possible that CRP suppresses the transformation of macrophages into foam cells via three distinct mechanisms; interference of oxLDL uptake, degradation of oxidized biomolecules, and maintenance of active cholesterol efflux.

Our observations do not contradict the current model that CRP and oxLDL are pro-atherogenic mediators for macrophages. This study demonstrates that either LPC, a PC-containing moiety in oxLDL, or CRP alone, activate NF-kB, and stimulate the generation of ROS, as well as pro-inflammatory mediators and cytokines in human macrophages [32-34]. Additionally, the study suggests a potential mechanism in which complex formation between CRP and PC-epitopes in oxLDL may alleviate oxidative and pro-inflammatory stress in macrophages, which could explain the findings of a number of previous studies. It has been shown that CRP forms a complex with E-LDL and inhibits E-LDL-induced formation of the membrane attack complex [35]. Moreover, the binding of CRP to apoptotic cells suppressed CRPinduced complement activation, while the production of tumour growth factor alpha, an anti-inflammatory cytokine, by apoptotic cells was unaffected [36].

\section{Conclusions}

In early and advanced stages of human atherosclerotic plaques, both CRP and oxLDL are co-localized with macrophages $[37,38]$. It is possible that the functional inhibition of CRP through complex formation with PCcontaining phospholipids and vice versa may not only retard the morphological change of macrophages into foam cells but also suppress the pro-inflammatory and oxidative activities of macrophages that can be triggered by either CRP or oxLDL alone. 


\section{Competing interests}

The authors declare that they have no competing interests.

\section{Authors' contributions}

$\mathrm{M}-\mathrm{KC}$, Contributed to the conception and design of the study and to the acquisition, analysis and interpretation of data.KH, Contributed to preparation of the manuscript. JR, Contributed to the conception and design of the study and to the acquisition, analysis and interpretation of data. YK, Contributed to the conception and design of the study and to the acquisition, analysis and interpretation of data. $\mathrm{KHH}$. Contributed to the conception and design of the study, to the acquisition, analysis and interpretation of data and to preparation of the manuscript. All authors read and approved the final manuscript.

\section{Acknowledgements}

This study was in part supported by grants 2010-288 and 2011-288 from the Asan Institute for Life Sciences, by grant number A050020 from the Korean Ministry of Health, by FPR02A624110 from Korean Ministry of Science, and by Cardiovascular Research Foundation Korea. M-K. Chang and K. Hartvigsen were supported by Scientist Development Grants 0330115N and 0630228N from the American Heart Association.

\section{Author details}

'Department of Medicine, University of California San Diego, La Jolla, CA, USA. ${ }^{2}$ University of Ulsan College of Medicine, Asan Medical Center, 388-1 Pungnap-2 dong Songpa-gu 138-736, Seoul, South Korea. ${ }^{3}$ Present address: Bayer Korea, 7th fl. Samsung-Boramae Omni Tower, 395-62, Sindaebang dong Dongzak-gu, Seoul, South Korea.

Received: 31 May 2012 Accepted: 17 September 2012

Published: 31 October 2012

\section{References}

1. Libby P, Ridker PM, Maseri A: Inflammation and atherosclerosis. Circulation 2002, 105:1135-1143.

2. Ridker PM, Hennekens $\mathrm{CH}$, Buring JE, Rifai N: C-reactive protein and other markers of inflammation in the prediction of cardiovascular disease in women. N Engl J Med 2000, 342:836-843.

3. Liuzzo G, Biasucci LM, Gallimore JR: The prognostic value of C-reactive protein and serum amyloid A protein in severe unstable angina. $N$ Engl J Med 1994, 331:417-424.

4. Sun H, Koike T, Ichikawa T, Hatakeyama K, Shiomi M, Zhang B, Kitajima S, Morimoto M, Watanabe T, Asada Y, et al: C-reactive protein in atherosclerotic lesions: its origin and pathophysiological significance. Am J Pathol 2005, 167:1139-1148.

5. Jialal I, Devaraj S, Singh U: Sources of CRP in atherosclerotic lesions. Am J Pathol 2005, 168:1054-1055.

6. Devaraj S, Du Clos TW, Jialal I: Binding and internalization of C-Reactive protein by Fcgamma receptors on human aortic endothelial cells mediates biological effects. Arterio Throm Vasc Biol 2005, 26:1359-1363.

7. Verma S, Devaraj S, Jialal I: Is C-reactive protein an innocent bystander or proatherogenic culprit? C-reactive protein promotes atherothrombosis. Circulation 2006, 113:2135-2150.

8. Chang MK, Binder CJ, Torzewski M, Witztum JL: C-reactive protein binds to both oxidized LDL and apoptotic cells through recognition of a common ligand: phosphorylcholine of oxidized phospholipids. Proc Natl Acad Sci USA 2002, 99:13043-13048.

9. Esterbauer H, Ramos P: Chemistry and pathophysiology of oxidation of LDL. Rev Physiol Biochem Pharmacol 1996, 127:31-64.

10. Steinbrecher UP, Pritchard PH: Hydrolysis of phosphatidylcholine during $\mathrm{LDL}$ oxidation is mediated by platelet-activating factor acetylhydrolase. J Lipid Res 1989, 30:305-315.

11. Steinbrecher UP, Parthasarathy S, Leake DS, Witztum JL, Steinberg D: Modification of low density lipoprotein by endothelial cells involves lipid peroxidation and degradation of low density lipoprotein phospholipids. Proc Natl Acad Sci USA 1984, 81:3883-3887.

12. Portman $\mathrm{OW}$, Alexander M: Lysophosphatidylcholine concentrations and metabolism in aortic intima plus inner media: effect of nutritionally induced atherosclerosis. J Lipid Res 1969, 10:158-165.

13. Yla-Herttuala S, Palinski W, Rosenfeld ME, Parthasarathy S, Carew TE, Butler S, Witztum $J$, Steinberg D: Evidence for the presence of oxidatively modified low density lipoprotein in atherosclerotic lesions of rabbit and man. J Clin Invest 1989, 84:1086-1095.

14. Macphee $\mathrm{CH}$, Nelson JJ, Zalewski A: Lipoprotein-associated phospholipase A2 as a target of therapy. Curr Opin Lipidol 2005, 16:442-446.

15. Han KH, Chang MK, Boullier A, Green SR, Li A, Glass CK, Quehenberger O: Oxidized LDL reduces monocyte CCR2 expression through pathways involving peroxisome proliferator-activated receptor gamma. J Clin Invest 2000, 106:793-802.

16. Han KH, Hong KH, Park JH, Ko J, Kang DH, Choi KJ, Hong MK, Park SW, Park SJ: C-reactive protein promotes monocyte chemoattractant protein1-mediated chemotaxis through upregulating CC chemokine receptor 2 expression in human monocytes. Circulation 2004, 109:2566-2571.

17. Erl W, Weber C, Zernecke A, Neuzil J, Vosseler CA, Kim HJ, Weber PC: Cyclopentenone prostaglandins induce endothelial cell apoptosis independent of the peroxisome proliferator-activatied receptor. Eur J Immunol 2004, 34:241-250.

18. Mullenix MC, Mortensen RF: Calcium ion binding regions in C-reactive protein: location and regulation of conformational changes. Mol Immunol 1994, 31:615-622.

19. Lee RT, Takagahara I, Lee YC: Mapping the binding areas of human Creactive protein for phosphorylcholine and polycationic compounds. J Biol Chem 2002, 277:225-232.

20. Bang R, Marnell L, Mold C, Stein MP, Clos KT, Chivington-Buck C, Clos TW: Analysis of binding sites in human C-reactive protein for Fc\{gamma\}RI, Fc\{gamma\}RIIA, and C1q by site-directed mutagenesis. J Biol Chem 2005, 280:25095-25102.

21. Wang $H$, Sui S: Dissociation and subunit rearrangement of membranebound human C-reactive proteins. Biochem Biophys Res Commun 2001, 288:75-79.

22. Pengal RA, Ganesan LP, Fang H, Marsh CB, Anderson CL, Tridandapani S: SHIP-2 inositol phosphatase is inducibly expressed in human monocytes and serves to regulate Fcgamma receptor-mediated signaling. J Biol Chem 2003, 278:22657-22663.

23. Swindle EJ, Coleman JW, DeLeo FR, Metcalfe DD: FcepsilonRI- and Fcgamma receptor-mediated production of reactive oxygen species by mast cells is lipoxygenase- and cyclooxygenase-dependent and NADPH oxidase-independent. J Immunol 2007, 179:7059-7071.

24. von Eckardstein A: Cholesterol efflux from macrophages and other cells. Curr Opin Lipidol 1996, 7:308-319.

25. Jessup W, Gelissen IC, Gaus K, Kritharides L: Roles of ATP binding cassette transporters $A 1$ and $\mathrm{G} 1$, scavenger receptor $\mathrm{BI}$ and membrane lipid domains in cholesterol export from macrophages. Curr Opin Lipidol 2006, 17:247-257.

26. Chang MK, Bergmark C, Laurila A, Horkko S, Han KH, Friedman P, Dennis EA, Witztum JL: Monoclonal antibodies against oxidized low-density lipoprotein bind to apoptotic cells and inhibit their phagocytosis by elicited macrophages: evidence that oxidation-specific epitopes mediate macrophage recognition. Proc Natl Acad Sci USA 1999, 96:6353-6358.

27. Singh SK, Suresh MV, Prayther DC, Moorman JP, Rusinol AE, Agrawal A: Creactive protein-bound enzymatically modified low-density lipoprotein does not transform macrophages into foam cells. J Immunol 2008, 180:4316-4322.

28. van Tits $L$, de Graaf J, Toenhake $H$, van Heerde W, Stalenhoef A: C-reactive protein and annexin A5 bind to distinct sites of negatively charged phospholipids present in oxidized low-density lipoprotein. Arterio Throm Vasc Biol 2005, 25:717-722.

29. Singh U, Dasu MR, Yancey PG, Afify A, Devaraj S, Jialal I: Human C-reactive protein promotes oxidized low density lipoprotein uptake and matrix metalloproteinase-9 release in Wistar rats. J Lipid Res 2008, 49:1015-1023.

30. Collot-Teixeira S, Martin J, McDermott-Roe C, Poston R, McGregor JL: CD36 and macrophages in atherosclerosis. Cardiovasc Res 2007, 75:468-477.

31. Kovacs A, Tornvall P, Nilsson R, Tegner J, Hamsten A, Bjorkegren J: Human $\mathrm{C}$-reactive protein slows atherosclerosis development in a mouse model with human-like hypercholesterolemia. Proc Natl Acad Sci USA 2007, 104:13768-13773.

32. Sheng F, Cheng L, Zeng Q, Gao W: Increased expression and activity of MMP-9 in C-reactive protein- induced human THP-1 mononuclear cells is related to activation of nuclear factor kappa-B. J Huazhong Univ Sci Technolog Med Sci 2009, 29:399-403.

33. Huang $X$, Zhang J, Liu J, Sun L, Zhao H, Lu Y, Wang J, Li J: C-reactive protein promotes adhesion of monocytes to endothelial cells via 
NADPH oxidase-mediated oxidative stress. J Cell Biochem 2012, 113:857-867.

34. Park CH, Kim MR, Han JM, Jeong TS, Sok DE: Lysophosphatidylcholine exhibits selective cytotoxicity, accompanied by ROS formation, in RAW 264.7 macrophages. Lipids 2009, 44:425-435.

35. Bhakdi S, Torzewski M, Paprotka K, Schmitt S, Barsoom H, Suriyaphol P, Han S, Lackner KJ, Husmann M: Possible protective role for C-reactive protein in atherogenesis. Circulation 2004, 109:1870-1876.

36. Gershov D, Kim S, Brot N, Elkon KB: C-reactive protein binds to apoptotic cells, protects the cells from assembly of the terminal complement components, and sustains an antiinflammatory innate immune response: implication for symmetric autoimmunity. J Exp Med 2000, 192:1353-1364.

37. Meuwissen M, van der Wal AC, Niessen HW, Koch KT, de Winter RJ, van der Loos C, Rittersman SZ, Chamuleau SA, Tijssen JG, Becker AE, et al:

Colocalisation of intraplaque $C$ reactive protein, complement, oxidised low density lipoprotein, and macrophages in stable and unstable angina and acute myocardial infarction. J Clin Pathol 2006, 59:196-201.

38. Torzewski J, Torzewski M, Bowyer DE, Frohlich M, Koenig W, Waltenberger J, Fitzsimmons C, Hombach V: C-reactive protein frequently colocalizes with the terminal complement complex in the intima of early atherosclerotic lesions of human coronary arteries. Arterioscler Thromb Vasc Biol 1998, 18:1386-1392

doi:10.1186/1476-9255-9-42

Cite this article as: Chang et al.: The pro-atherogenic effects of macrophages are reduced upon formation of a complex between C-reactive protein and lysophosphatidylcholine. Journal of Inflammation 2012 9:42.

\section{Submit your next manuscript to BioMed Central and take full advantage of:}

- Convenient online submission

- Thorough peer review

- No space constraints or color figure charges

- Immediate publication on acceptance

- Inclusion in PubMed, CAS, Scopus and Google Scholar

- Research which is freely available for redistribution 